\title{
Design and Analysis on Reduced Switching Frequency Current Mode Control Isolated Power Converters for Light Load Efficiency
}

\author{
Yu Ruiyang \\ University of Hong Kong \\ Department of EEE, \\ yry721@eee.hku.hk
}

\author{
M.H. Pong \\ Senior Member, IEEE \\ University of Hong Kong \\ Department of EEE, \\ mhp@eee.hku.hk
}

\begin{abstract}
This paper focus on improving light load efficiency of isolated DC/DC converters. A mixed signal control platform is proposed to implement multiple-mode variable frequency control. An 8-bit Micro Controller Unit MCU is used in the platform to provide adaptive control schemes and cost effectiveness digital solutions. Small signal analysis is covered to explain frequency modulation effects. Control of isolation transformer flux swing to avoid saturation is also implemented, to provide safe operation both in steady and transient states. A 300 Watt prototype Two-FET forward converter is built up to verify the proposed mixed signal control platform.
\end{abstract}

Index Terms - Isolated DC/DC converters, Multiple Modes, Light Load Efficiency, Pulse Frequency Modulation PFM, Mixed Signal Control.

\section{INTRODUCTION}

Most of electronic devices operate at light load conditions for most of the time, for example, printers, adapters, LCD TVs and desktop PCs. Thus, light load efficiency becomes a major concern in switch mode power supply design stage. Reducing switching frequency is a popular method to increase light load efficiency. In order to have good performance over a wide range of load, multiple-modes are often implemented in the power converter, from standby burst mode (Below 1\% rated load), light load (1\% to $20 \%$ rated load) to full load.

Lots of control methods were implemented in buck converter to boost up the light load efficiency [1-6]. There are some commercialized ICs [7-9] to implement these functions on $\mathrm{DC} / \mathrm{DC}$ isolated flyback converters. However, flyback converters only apply small power conversion applications.

In this paper, we focus on designing $\mathrm{DC} / \mathrm{DC}$ isolated converter operating in variable frequency mode. A 300 Watt Two-FET forward converter is built up to demonstrate the merits of variable frequency control at light load conditions. In $\mathrm{DC} / \mathrm{DC}$ isolated converter light load conditions, several problems are caused by reducing switching frequency, such as dynamic performance on frequency modulation and avoiding isolation transformer saturation. These problems need to be solved by adaptive control schemes.

A mixed signal control platform is proposed to implement multiple-mode variable frequency control. An 8-bit Micro Controller Unit MCU is used in the platform to provide adaptive control schemes. The proposed mixed signal control platform also highlights cost effectiveness digital solution for isolated DC/DC converters.

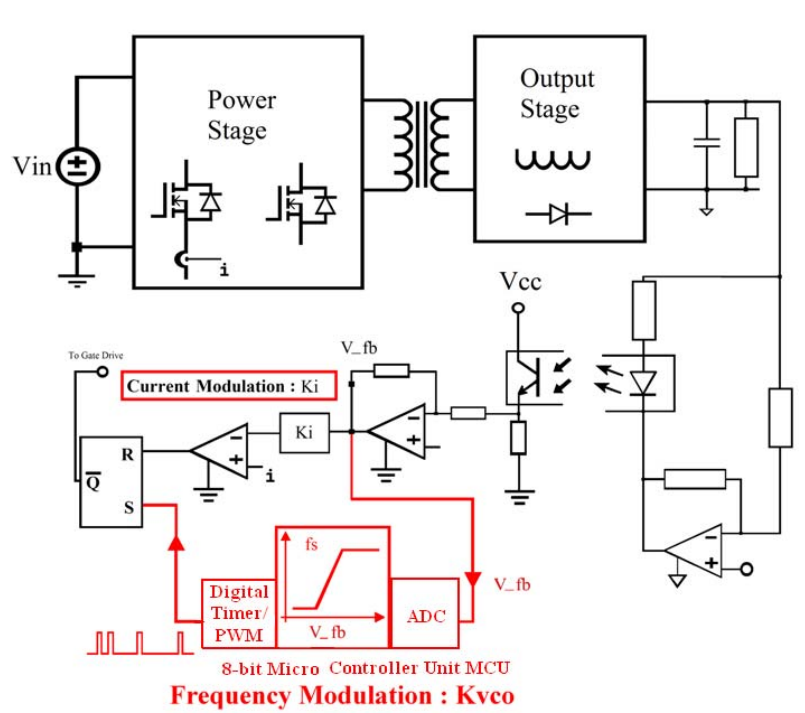

Figure 1 A mixed signal Platform for variable frequency Control

\section{STEADY STATE ANALYSIS}

\section{A. Operating Profile}

In conventional fixed frequency peak current mode converter, the switching frequency is kept as a constant value. In order to boost up light load efficiency, switching frequency needs to be reduced at light load condition. Fig. 1 shows an isolated $\mathrm{DC} / \mathrm{DC}$ converter with multiple modes. At light load, variable frequency mode is activated by MCU. In an isolated $\mathrm{DC} / \mathrm{DC}$ converter the feedback signal $\mathrm{V}$ fb is a critical value to reduce switching frequency. At light load conditions, while the converter is operating at DCM. The peak current is controlled proportional by the control signal. In the meantime, the switching frequency is also reduced because of lower input scale of voltage controlled oscillator $\mathrm{VCO}$ (programmed into MCU), as shown in fig. 2.

In isolated DC/DC converters, isolation between secondary side and primary side must be considered. The controller ICs, such as those in [7-10] were typically implemented in the primary side. Please note that the feedback signal is proportional to the peak current at every switching cycle. This structure makes it easy to get load information by sensing the feedback signal only. What's more, it is difficult to directly sensing secondary side inductor current or load 
current and translates the exact value from secondary side sensor to primary side controller ICs.

The operating profile of MCU is programmed into an 8-bit microcontroller and connects to primary side controller IC UCC38C44 [10]. Detail implementations of this structure will be discussed later.

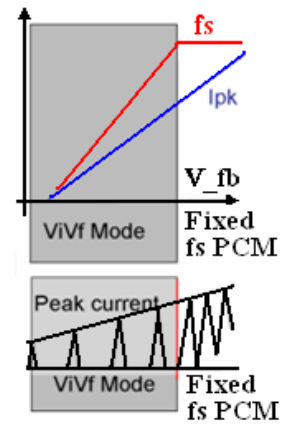

Figure 2 variable peak current variable frequency mode ( ViVf mode )
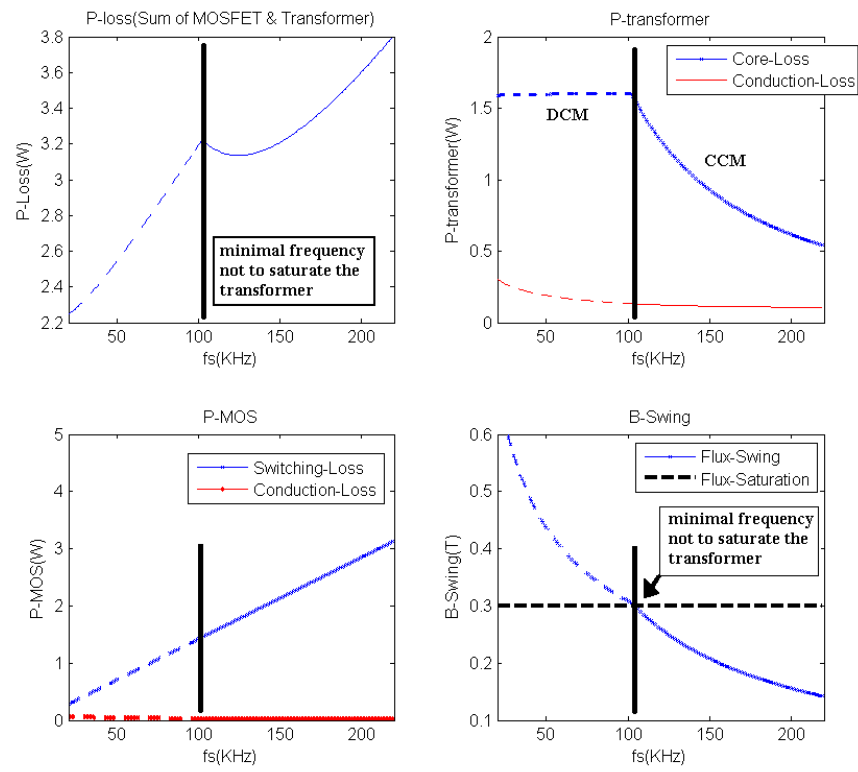

Figure 3.a Losses analysis at $20 \%$ load condition

\section{B. Efficiency Analysis}

Generally speaking, the major losses in light load conditions are switching losses, and magnetic core losses. Conduction losses are low in light load conditions. Major switching losses of high voltage power MOSFETs, at light load conditions, are charging and discharging the output capacitance Coss of MOSFETs. Transformer core losses includes hysteresis losses and eddy current loss. The core loss empirical equation $P_{c o r e}=a f^{c} B_{a c}{ }^{d}$ is provided by ferrite vendors, and can be calculated directly.

The isolated DC/DC power converter operates in DCM at
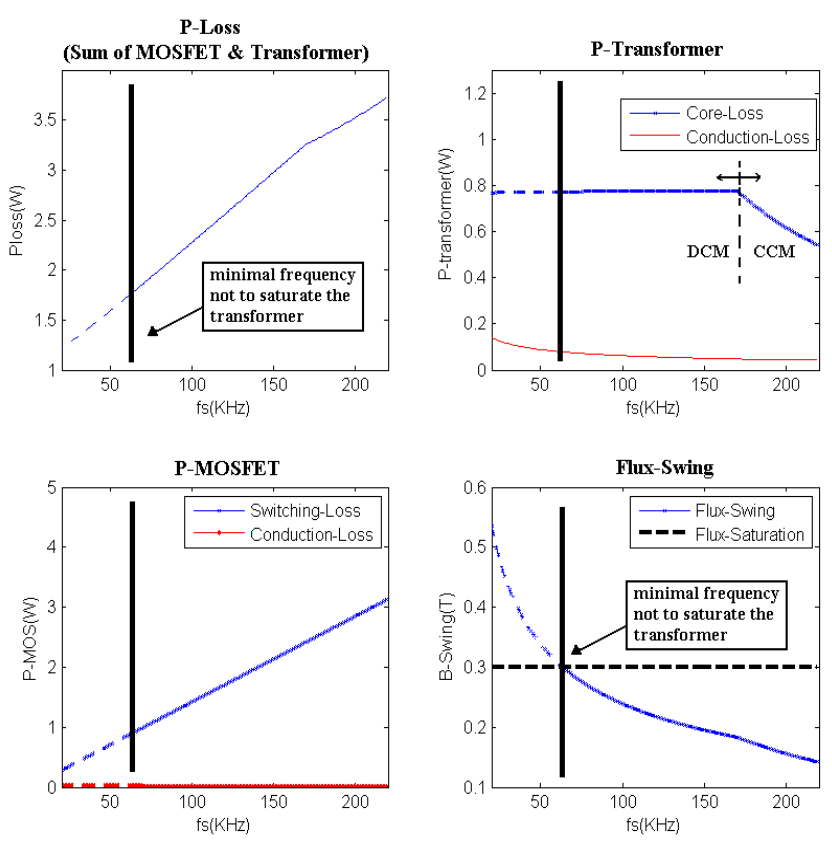

Figure 3.b Losses analysis at $10 \%$ load condition P-Loss
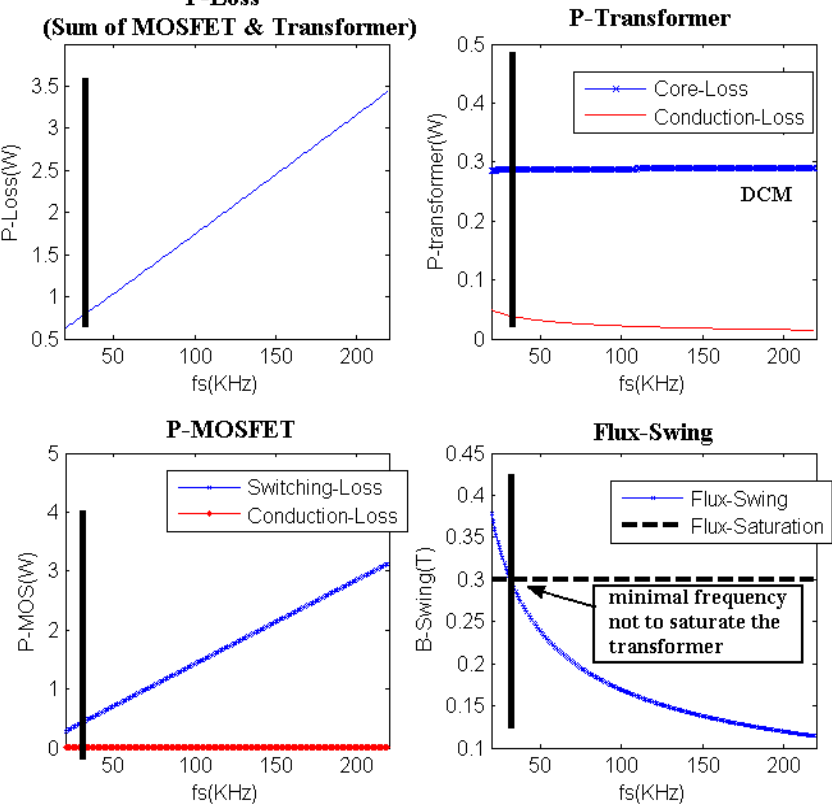

Figure 3.c Losses analysis at $5 \%$ load condition light load conditions. Fig 3.a shows loss analysis at $20 \%$ load. Circuit parameters are accordance with Table.1 (in Experimental Results Section) At 20\% load condition, the converter is operating at $\mathrm{CCM}$ when switching frequency is higher than $100 \mathrm{KHz}$. Reducing switching frequency do not improve the overall efficiency (up-left diagram in fig.3.a), because core loss increases if switching frequency reduces(upper-right diagram in fig.3.a). However, at $10 \%$ load condition, at high switching frequency condition (Higher than $170 \mathrm{KHz}$ ), the converter is operating in CCM. Reducing switching frequency only slightly increases core losses. While the converter is operating in DCM (lower than 170 
$\mathrm{KHz}$ ), core losses almost keeps the same even if switching frequency decreases. For high voltage power MOSFET, reducing switching frequency can significantly reduce switching losses. Then, reducing switching frequency can improve overall efficiency. Please note the minimal switching frequency applies at $20 \% 10 \% 5 \%$ load condition is also shown. Flux swing of isolation transformer must be kept below $0.3 \mathrm{~T}$, preventing the isolation transformer from saturation. This minimal frequency is only for steady state. Large signal transient require maximum duty cycle for each operating frequency and will be discussed later.

At $5 \%$ load condition, the same principle can also be applied and is shown in fig.3.c. Reducing switching frequency can significantly improve light load efficiency.

\section{DYNAMIC ANALYSIS}

In order to optimize efficiency over a wide range of load, multi-mode operation should be used. In reducing switching frequency mode, constant on time (CTon) or constant peak current (CIpk) mode cannot fulfill good performance through $5 \%$ to $20 \%$ rated load. What we desire is the on time or peak current is adaptive from load variation, as shown in figure 2. At these conditions, both peak current and switching frequency are modulated, which is variable peak current and variable frequency mode (ViVf). However, dynamic response at ViVf mode differs from constant frequency peak current (PCM) mode or constant peak current variable frequency mode.

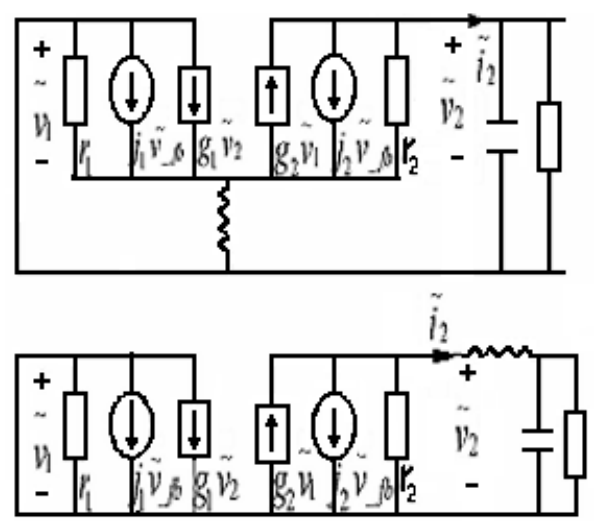

Figure 4, based on [13], small signal analyses on ViVf mode

Based on [12-15] fig.4, a model is derived to consider $\mathrm{Ki}$ and Kvco both at the same time. The method is based on partial differentiation.

In order to decompose ViVf mode, firstly we assume:

$$
\begin{gathered}
v_{f b}=x=y \\
\tilde{v}_{f b}=\tilde{x}=\tilde{y}
\end{gathered}
$$

Represent current modulation part with variable $\mathrm{x}$, and represent frequency modulation part with $\mathrm{y}$.

$$
\begin{gathered}
i_{p k}=K_{i} v_{f b}=K_{i} x \\
f_{s}=K_{v c o}(s)\left(v_{f b}-a\right)=K_{v c o}(s)(y-a)
\end{gathered}
$$

As shown in fig.4, j2 is related to feedback signal to determine i2, and also related to control to output voltage

A buck boost converter can be written as (5).

$$
i_{2}=\frac{1}{2} \frac{L i_{p k}(x)^{2} f_{s}(y)}{v_{2}}
$$

To get the small signal model of two variable $\mathrm{x}$ and $\mathrm{y}$ (actually $\mathrm{x}$ and $\mathrm{y}$ both equal to $\mathrm{Vfb}$ ), a general method is to use partial differentiation.

$$
\tilde{i}_{2}=\left(\frac{\partial i_{2}}{\partial x}\right) \tilde{x}+\left(\frac{\partial i_{2}}{\partial y}\right) \tilde{y}
$$

The current modulation part is shown in (7)

$$
\frac{\partial i_{2}}{\partial x}=\left.\left.\frac{L}{2 v_{2}} f_{s}(y)\right|_{\substack{y=V_{f b} \\ s=0}} \frac{\partial i_{p k}^{2}(x)}{\partial x}\right|_{x=V_{f b}}
$$

The frequency modulation part is shown in (8)

$$
\frac{\partial i_{2}}{\partial y}=\left.\left.\frac{L}{2 v_{2}} i_{p k}^{2}(x)\right|_{x=V_{f b}} \frac{\partial f_{s}(y)}{\partial y}\right|_{y=V_{f b}}
$$

Rearrange (6) (7) (8), we can get (9)

$$
i_{2}=\frac{2 I_{2}}{V_{f b}} \tilde{v}_{f b}+\frac{L I_{p k}^{2} K_{v c o}(s)}{2 V_{2}} \tilde{v}_{f b}
$$

Actually, (9) is the sum of (7) and (8). In another word, we can decompose ViVf mode into two parts: peak current modulation (PCM) part and frequency modulation (CIpk) part. They fulfill the relationship that, as shown in fig5.a fig.5.b:

$$
G_{V i V f}(s)=G_{P C M}(s)+G_{C I p k}(s)
$$

We can also calculate the buck ViVf mode using similar method.

$$
\begin{gathered}
i_{2}=\frac{L i_{p k}(x)^{2} f_{s}(y)}{2} \frac{v_{1}}{v_{2}\left(v_{1}-v_{2}\right)} \\
i_{2}=\left(\frac{2 I_{2}}{V_{f b}}+\frac{L I_{p k}^{2} K_{v c o}(s)}{2}\right) \frac{V_{1}}{V_{2}\left(V_{1}-V_{2}\right)} v_{f b}
\end{gathered}
$$

The buck ViVf mode also fulfill (10)

Proper design of Kvco should be chosen to implement variable frequency control, as shown in fig.6. 


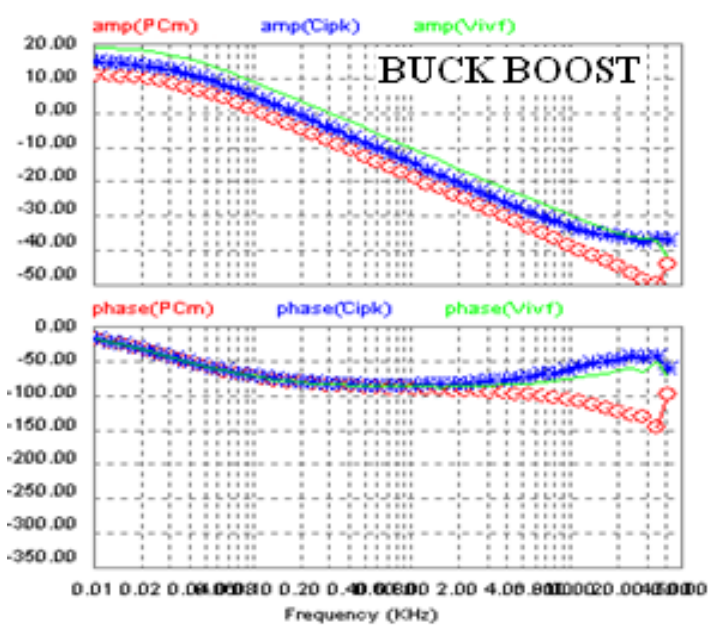

Figure 5.a : ViVf DCM (Switch Model) Green line; PCM Red Line; CIpk Mode Blue Line, $K_{-}$vco $(0)=110 \mathrm{~Hz} / \mathrm{mV}$ Frequency Modulation Dominated Case

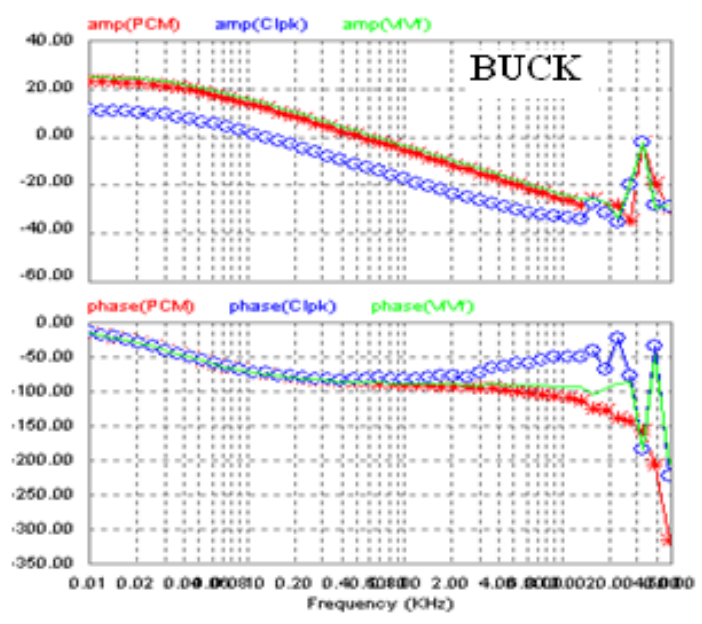

Figure 5.b: ViVf DCM (Switch Model) Green line; PCM Red Line; CIpk Mode Blue Line, K_vco(0) $=14 \mathrm{~Hz} / \mathrm{mV}$ Peak Current Dominated Case

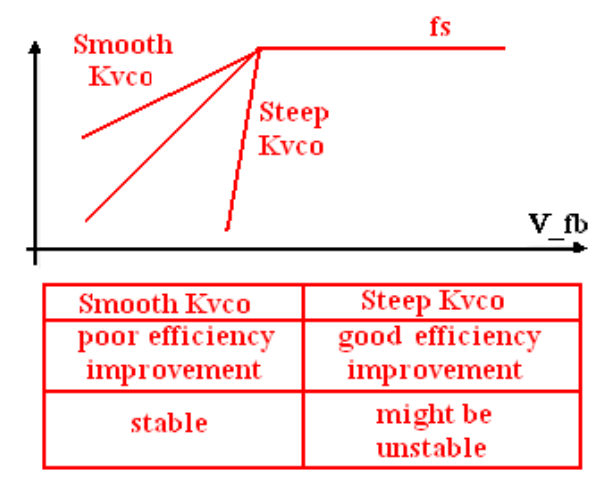

Figure 6 Smooth Kvco and Steep Kvco

\section{MiXed Signal CONTROL PlatForm}

As discussed in the previous section, a variable frequency isolated $\mathrm{DC} / \mathrm{DC}$ converter needs controlling multiple variables, such as switching frequency, max duty cycle, Kvco and etc. While adding a frequency loop into the conventional peak current mode, it is desirable to implement adaptive frequency control algorithms rather than simply analog VCO.

Luckily, with the development of digital techniques, 8-bit micro-controller MCU is a promising solution. The 8-bit MCU can provide low cost, fast ADC sampling speed (conversion time $3.3 \mu \mathrm{s}$, fast enough for $\mathrm{DC} / \mathrm{DC}$ isolated converter bandwidth), small power consumption and small size (8-pin SOIC package) [11].

Because the main control loop is covered by analog circuits, the digital MCU only needs to sample the feedback signal and generate pre-programmed clock frequency and max duty cycle commands.

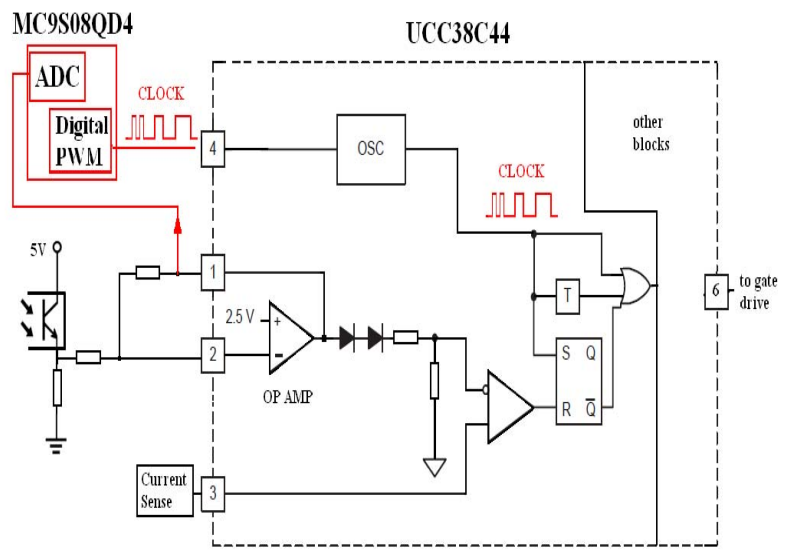

Figure 7 mixed signal platform with a MCU MC9S08QD4 [11] and a current mode controller UCC38C44 [10]

The hardware implementations of mixed signal control platform are shown in fig.7. In addition to variable frequency control, the proposed mixed signal platform also has the following merits. Because the MCU is at primary side, together with current mode controller ICs, it is based on convention current mode controller. It does not need house keeping power supply to start up or power the digital controller. It is also possible to sense primary side information without isolation consideration.

The operating profile of MCU is shown in fig.8. After $\mathrm{ADC}$ get the sampled value of feedback signal $\mathrm{Vfb}, \mathrm{MCU}$ will calculate the switching frequency (counter value of digital PWM ) and corresponding max duty cycle ( max on time in this case) to avoid transformer saturation, as shown in fig.9 (The clock frequency is twice the converter switching frequency). A hysteresis band is programmed into the operating profile, to make sure the converter does not hop between two modes. Kvco also should be considered in this stage. Steep Kvco would cause the converter unstable and generate unexpected audible noise in experimental setups. 
The stability design guideline for $\mathrm{K}_{\mathrm{vco}}$ is presented in the previous section.

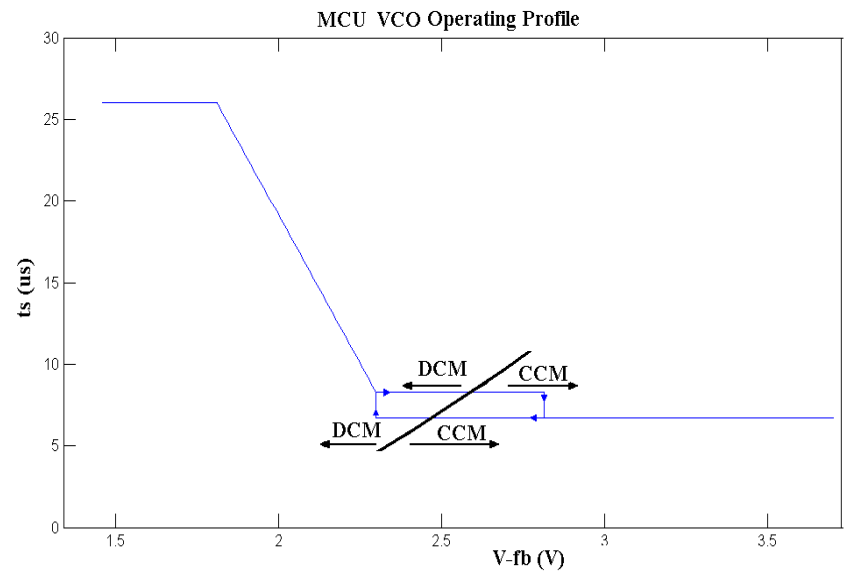

Figure 8 Operating profile of MCU to implement variable frequency control

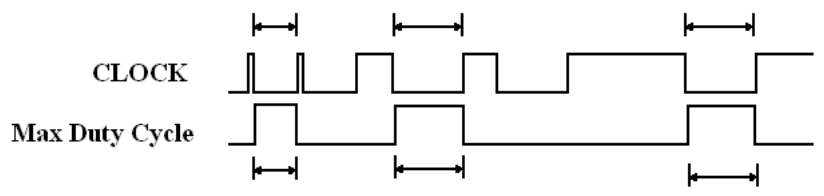

Figure 9 Clock and max duty cycle commands, the switching frequency is half of the clock frequency

At steady states, the converter works stably both in variable frequency and fixed frequency mode. During step up transient, the MCU needs to sample the feedback signal and set the digital PWM counter. Yet, these processes introduce a little delay from low frequency to high frequency. Special care on these effects during step up must be considered [16] [17].

A conclusion at this section can be made that a mixed signal platform is proposed. At light load conditions, the clock can be well controlled by MCU, both the frequency and max duty cycle. The mixed signal control platform is based on conventional primary side current mode controller structure and it is cost effectiveness.

\section{EXPERIMENTAL RESULTS}

A prototype 300Watt Two-FET-Forward single output Converter with $300-400 \mathrm{~V}$ input voltage and $12 \mathrm{~V}$ output voltage is built. The circuit parameters are summarized in table. 1 .

The Efficiency of fixed frequency converter and variable frequency converter are shown in fig.10. The efficiency improvement below 10\% load is significant. The efficiency improvement could be further if synchronous rectifiers are used instead of Schottky Diodes.

\begin{tabular}{|l|c|l|}
\hline \multicolumn{3}{|c|}{ Two-FET-Forward Converter } \\
\hline Primary MOSFET & IPP50R140CP & 2 at primary side \\
\hline Isolation Transformer & EER28/17/11 N87 & Turn Ratio 48:5 \\
\hline Output Capacitor & $2200 \mu \mathrm{F}$ & Electrolytic Cap \\
\hline Output Inductor & $8 \mu \mathrm{H}$ & EE36/18/11 N87 \\
\hline Output Rectifier & MBR20100CTG & $2 * 2$ at Output \\
\hline Output Voltage/Current & $12 \mathrm{~V} / 0-25 \mathrm{~A}$ & \\
\hline
\end{tabular}

Table 1

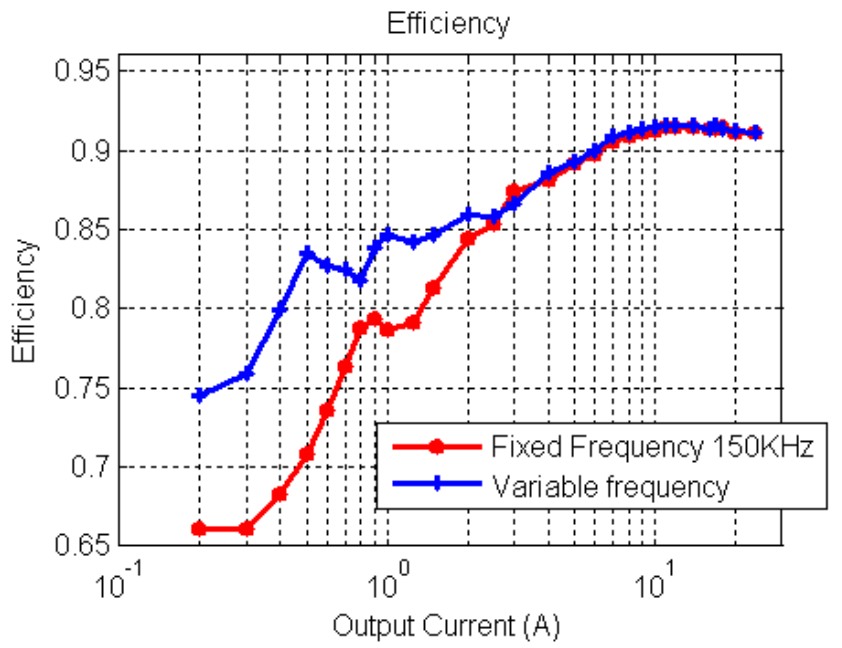

Figure 10 Efficiency improvements at light load, VIN $=370 \mathrm{~V}$

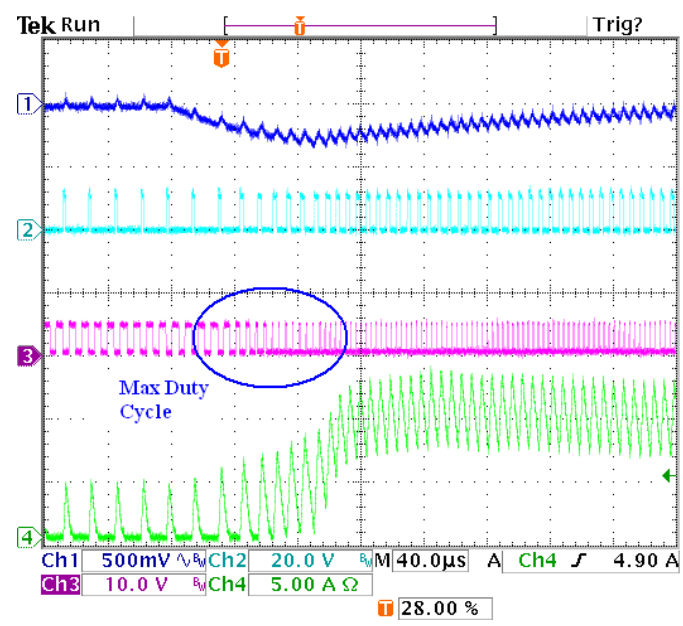

Figure 11.a. Step up transient response $0.7 \mathrm{~A}$ to $8 \mathrm{~A}$

Step up transients (fig.11.a and fig11.b) are tested to exam the isolated $\mathrm{DC} / \mathrm{DC}$ converter does not saturate during transient response. The voltage drops during transient responses are also shown. The converter works stably both in variable frequency ViVf mode and fixed frequency mode 


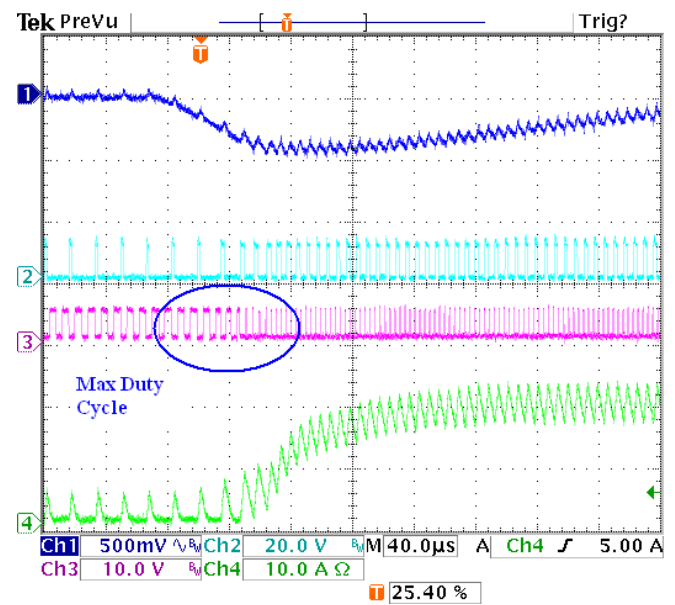

Figure11.b. Step up transient 0.7A to 16A

\section{CONCLUSIONS}

This paper focuses on improving light load efficiency of isolated DC/DC converters. A mixed signal control platform is proposed to implement multiple-mode variable frequency control. An 8-bit Micro Controller Unit MCU is used in the platform to provide adaptive control schemes and cost effectiveness digital solution. Small signal analysis is covered to frequency modulation effects of ViVf mode. Control of isolation transformer flux swing to avoid saturation is also implemented, to provide safe operation both in steady state and transient. A 300 Watt prototype Two-FET forward converter is built up to verify the proposed mixed signal control platform. Efficiency improvements and avoiding transformer saturation during transient are presented.

\section{REFERENCES}

[1] Xunwei Zhou, Mauro Donati, Luca Amoroso, Fred C. Lee. "Improved Light-Load Efficiency for Synchronous Rectifier Voltage Regulator Module". IEEE TRANSACTIONS ON POWER ELECTRONICS, VOL. 15, NO. 5, SEPTEMBER 2000

[2] Barry Arbetter, Robert Erickson, and Dragan Maksimovic "DC-DC Converter Design for Battery-Operated System” IEEE PESC 1995

[3] Robert Erickson, Dragan Maksimovic "High Efficiency DC-DC Converters for battery-Operated System with Energy Management" http://ece-www.colorado.edu/ rwe/papers/EnergyMangmt.pdf

[4] Jaber A. Abu Qahouq, Osama Abdel-Rahman, Lilly Huang, and Issa Batarseh, "On Load Adaptive Control of Voltage Regulators for Power Managed Loads: Control Schemes to Improve Converter Efficiency and Performance", IEEE TRANSACTIONS ON POWER ELECTRONICS, VOL. 22, NO. 5, SEPTEMBER 2007

[5] Osama Abdel-Rahman, Jaber A. Abu Qahouq, Lilly Huang, and Issa Batarseh, "Analysis and Design of Voltage Regulator With Adaptive FET Modulation Scheme and Improved Efficiency" TRANSACTIONS ON POWER ELECTRONICS, VOL. 23, NO. 2, MARCH 2008

[6] Xu Zhang and Dragan Maksimovic, "Digital PWM/PFM Controller with Input Voltage Feed-Forward for Synchronous Buck Converters" APEC.2008

[7] Power Integrations "TOP-SWITCH -GX Enhanced EcoSmart, Integrated Off-Line Switcher with Advanced Feature Set and Extended Power Range"

[8] Infineon "ICE2AS01/S01G, ICE2BS01/S01G Off-Line SMPS Current Mode Controller"

[9] Fairchild Semiconductor "Applying SG6846 to Control a Flyback Power Supply with Surge Current Output"
[10] UCC38C44 Datasheet, Texas Instruments, http://focus.ti.com/docs/prod/folders/print/ucc38c44.html

[11] MC9S08QD4 Datasheet, Freescale, http://www.freescale.com/

[12] V. Vorperian, "Simplified Analysis of PWM Converters Using the Model of the PWM Switch, Part II: Discontinuous Conduction Mode," IEEE Transactions on Aerospace and Electronic Systems, vol. 26, no. 3, May 1990

[13] Robert W. Erickson,Dragon Maksimovie, "Fundamental of Power Electronics" (Second Edition) ) Kluwer Academic Publishers. PP. 478

[14] R. B. Ridley, "A new small-signal model for current-mode control", $\mathrm{PhD}$. dissertation, Virginia Polytechnic Institute and State University, 1990

[15] R. B. Ridley, "A new continuous-time model for current-mode control with constant frequency, constant on-time, and constant offtime, in CCM and DCM" in Proceedings of 1990 IEEE Power Electronics Specialists Conference, pp. 382-389, 1990.

[16] J.Sun, D.M.Mitchell, D.E.Jenkins, "Delay effects in averaged modeling of PWM converters" IEEE PESC 1999.

[17] Pit-Leong Wong; Lee F.C. "switching action delays in voltage regulator Modules", Seventeenth Annual IEEE Applied Power Electronics Conference and Exposition, Volume 2, 10-14 Page(s): 675 - 678 vol.2, March 2002 